\title{
A Rare Form of Melanoma Masquerading as a Diabetic Foot Ulcer: A Case Report
}

\author{
Susan Thomas, ${ }^{1}$ Yuan-Xiang Meng, ${ }^{1}$ Vijaykumar G. Patel, ${ }^{2}$ and Gregory Strayhorn ${ }^{1}$ \\ ${ }^{1}$ Department of Family Medicine, Morehouse School of Medicine, 1513 East Cleveland Avenue, \\ Building 100, Suite 300A, Atlanta, GA 30344, USA \\ ${ }^{2}$ Department of Surgery, Morehouse School of Medicine, 720 Westview Drive SW, Atlanta, \\ GA 30310, USA \\ Correspondence should be addressed to Yuan-Xiang Meng,ymeng@msm.edu
}

Received 12 December 2011; Accepted 29 January 2012

Academic Editor: C. Capella

Copyright (๑) 2012 Susan Thomas et al. This is an open access article distributed under the Creative Commons Attribution License, which permits unrestricted use, distribution, and reproduction in any medium, provided the original work is properly cited.

Background. Acral lentiginous melanoma (ALM) is a less-common form of melanoma in US, and it accounts for about $5 \%$ of all diagnosed melanomas in US. ALM is often overlooked until it is well advanced because of the lesion's location and its atypical appearance in the early stages. We present a case of ALM initially presented as a diabetic foot ulcer. Case Report. An 81-year-old man initially presented to the primary care clinic with a right foot diabetic ulcer. There was a large plantar, dark-colored ulcer that bled easy. Initial excision biopsy revealed Clark's Level IV ALM. Subsequent definitive wide excision and sentinel node biopsy confirmed ALM with metastasis to inguinal lymph nodes (stage IIIb). The treatment included wide margin excision of the lesion with en bloc amputations of 4 th and 5th toes, followed by adjuvant chemotherapy. Discussion. The development of ALM may potentially relate to diabetes as a reported higher prevalence of diabetes with ALM patients. Conclusion. The difficulty in early diagnosing of ALM remains as a formidable challenge particularly in diabetic patients who commonly develop plantar foot ulcers due to the diabetic neuropathy. This case reiterates the importance of a thorough foot exam in such patients.

\section{Introduction}

Diabetic patients have been estimated to have a lifetime risk of $15 \%$ of developing a neuropathic foot ulcer. Since diabetic foot ulcers are a common occurrence and biopsy of the ulcers is rarely performed, this poses significant challenges in the diagnosis of acral lentiginous melanoma in these patients where diagnosis is often delayed.

We report a case of a diabetic patient who presented at the primary care clinic for a routine follow-up visit with a compliant of an infected ulcer in his right foot which was present for six months. Biopsy confirmed acral lentiginous melanoma, and the patient underwent definitive treatment.

\section{Case Report}

An 81-year-old African-American male with past medical history of hypertension and diabetes was briefly lost follow up for 9 months. He presented to our primary care clinic for his routine follow-up examination with complaints of a progressively worsening infected right foot ulcer for over six months. Patient also admitted to having pain and foul smelling drainage from the ulcer. Patient denied any tobacco or alcohol use. Physical exam was unremarkable except for an ulcer on the plantar aspect on his right forefoot measuring $6 \times 5 \mathrm{~cm}$ with an ulcerated area at the base of fourth and fifth metatarsal involving the interdigital cleft and extending to the forefoot (Figure 1). The ulcer was necrotic, black with bleeding and minimal purulent drainage. The patient was started on oral antibiotics with local wound care and surgical consultation requested. Outpatient surgical evaluations revealed a black eschar with punctuate areas of bleeding after the removal of the eschar. The patient was admitted to the hospital for surgical debridement of the presumptive diabetic necrotic ulcer. Laboratory studies including Creactive protein (CRP) were within normal limits. His hemoglobin A1C was 5.6\% indicating excellent control of his diabetes. Radiographic studies of the foot did not show air in 


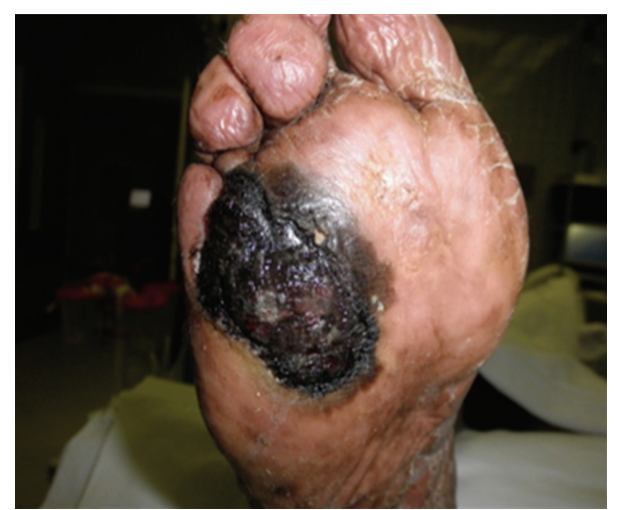

Figure 1: Gross view of the skin lesion on the plantar. The lesion measures $6 \times 5 \mathrm{~cm}$ with an ulcerated area at the base of fourth and fifth metatarsal involving the interdigital cleft and extending to the forefoot.

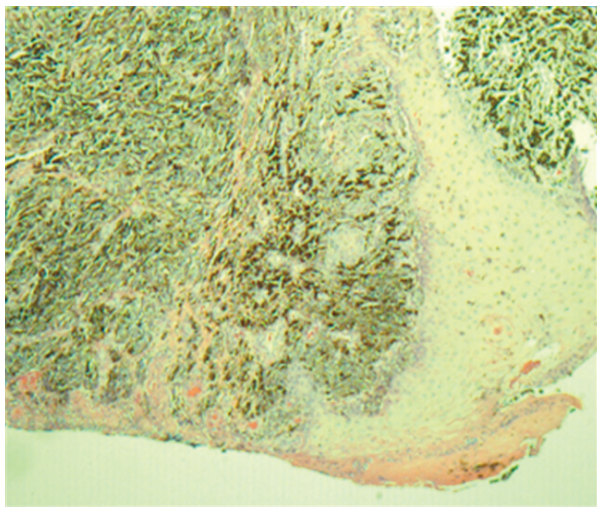

FIGURE 2: Thickened epidermis ulcerated with many heavily pigmented malignant melanocytes ( $\mathrm{H}$ and $\mathrm{E}$ Stains, $40 \times$ ).

the soft tissue, bony involvement, or signs of osteomyelitis. In the operating room under careful examination, the edges of the lesion were irregular with hyperpigmentation highly suggestive of a malignancy. An excision biopsy with $2 \mathrm{~mm}$ margin was sent for frozen section and pathology evaluation. Pathologic diagnosis was acral lentiginous melanoma. The tumor had an ulcerated surface that permeated the papillary and reticular dermis without permeation of subcutaneous tissue, suggestive of a Clarke level 4 (Figures 2, 3, 4, and 5). Maximum tumor thickness was $3.5 \mathrm{~mm}$, and mitotic index was $<1 / \mathrm{mm}^{2}$. A positron emission tomography/computed tomography (PET/CT) was negative for metastatic disease. A definitive procedure was subsequently performed that included en bloc left fourth and fifth toe amputation and wide excision of the previously excised melanoma along with sentinel lymph node biopsy after localizing the node with radioscintigraphy. Patient's sentinel lymph node biopsy was positive for lymph node metastasis (Figures 6 and 7), and his tumor staging, according to the American Joint Committee on Cancer (AJCC) system of TNM (tumor, node, and metastasis) classification, was stage IIIb (T3bN1bM0). Patient refused formal groin and iliac lymph node dissection and was refereed to hematology oncology for chemotherapy treatment with interferon.

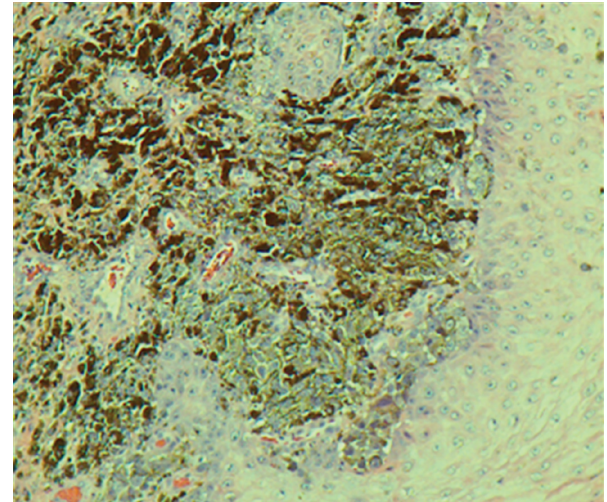

FIgURE 3: Epidermis and dermis with pigmented malignant melanocytes ( $\mathrm{H}$ and $\mathrm{E}$ stains, $100 \times$ ).

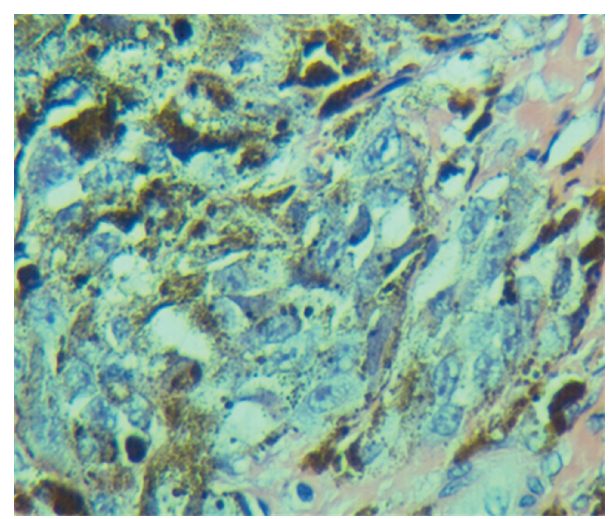

FIgure 4: Atypical tumor cells, some pigmented, some not, with large irregular nuclei with large nucleoli. Spindled and round tumor cells. Heavy cytoplasmic melanin pigment ( $\mathrm{H}$ and $\mathrm{E}$ stains, $400 \times$ ).

\section{Discussion}

The term acral lentiginous melanoma (ALM) was first described by Reed [1] as a subtype of melanoma. It was so named because of its predilection of acral (distal) areas of the body, particularly the palms, soles and the subungual areas, and its distinct radial or "lentiginous" growth phase. ALM represents the rarest of the four subtypes of cutaneous melanoma and yet is the most common variety diagnosed on the foot [2]. Reed described its diagnosis as being based on its histological, intradermal features showing a diffuse proliferation of large atypical melanocytes along the epidermal-dermal junction which is dispersed in a lentiginous pattern with marked acanthosis and elongation of the rete ridges. Research data have demonstrated that melanomas in acral locations account for only $1-7 \%$ of all cutaneous melanomas in Caucasians but have been shown to be significantly higher in Asian [3], Chinese [4], Japanese [5], Middle Eastern [6], and African populations [7]. ALM occurs equally across all races, predominantly on an area that seldom receives much sun exposure and suggests that the etiology is different from other subtypes of melanoma. However, Green et al. undertook a case control study of 275 


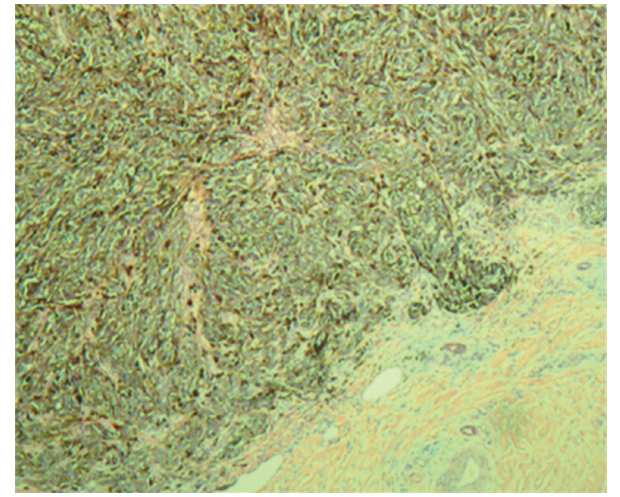

FIGURE 5: Dermal involvement of tumor cells with uninvolved adjacent deep dermis ( $\mathrm{H}$ and $\mathrm{E}$ stains, $40 \times$ ).

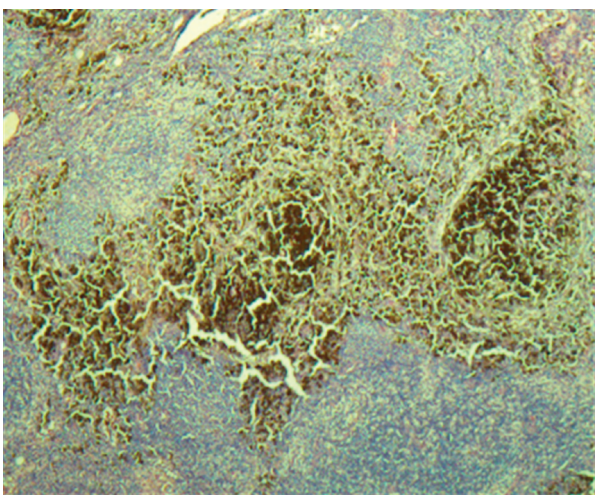

FIGURE 6: Right groin sentinel lymph node with heavy tumor cell involvement ( $\mathrm{H}$ and $\mathrm{E}$ stains, $40 \times$ ).

melanomas diagnosed on the soles and palms to investigate risk factors [8]. Interestingly, they found that sun exposure was a significant risk factor in the development of ALM despite their plantar and nail bed location. Furthermore, a high mole count on the soles and elsewhere on the body were associated risk factors ( $\mathrm{RR}=6.395 \%$ CI 2.5-15.6). Reinforcing this belief, other studies have demonstrated that increased sun exposure in an individual leads to the development of higher numbers of moles, especially in children [9]. The patient presented here denies any unusual or increased sun exposure. Even though trauma often drew attention to this type of lesion because of the anatomic location, there was no evidence to define it as an etiological factor [10]. Most common clinical features include change in size, color or pattern, and bleeding [11]. Misdiagnosis is a common feature of melanoma on the foot, but ALM in particular has been shown to be more likely misdiagnosed than other subtypes of the disease [12] with a reported rate between $33-37 \%[13,14]$. One of characteristics of ALM is slow growth. However, the patient we presented here reported the foot ulcer developed for six months only, and he was also under care by a podiatrist 3 months before the ulcer development. One of possibilities for the relatively fast growth of the ALM may point to the diabetes although our patient's diabetes has been well controlled. The study on the

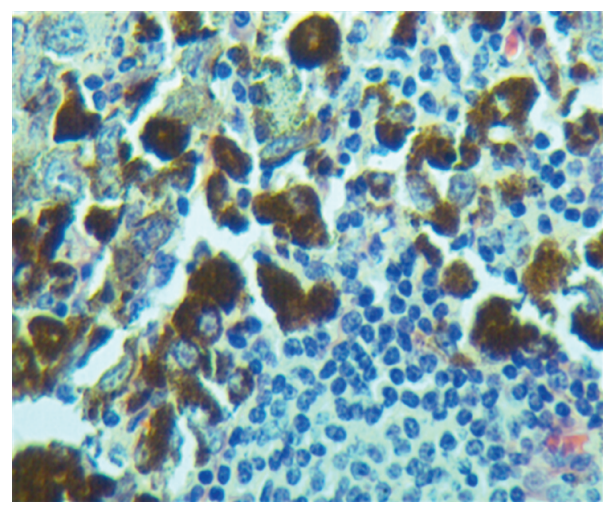

FIgURE 7: Tumor cells contrasted with benign lymphocytes of lymph node (Hand E stains, $400 \times$ ).

melanoma at the Singapore reported higher prevalence of diabetes with ALM patients [15].

\section{Conclusion}

ALM is an uncommon melanoma that can occur in the foot. Early diagnosis and appropriate referral for treatment makes a significant difference in the survival rate and prognosis of the patient. The difficulty in diagnosing it makes it a formidable challenge, especially in this case where it presents as a diabetic foot ulcer. This case once again reiterates the importance of a thorough foot exam in a diabetic patient at each clinic visit.

\section{Abbreviations}

$\begin{array}{ll}\text { ALM: } & \text { Acral lentiginous melanoma } \\ \text { US: } & \text { United States } \\ \text { CRP: } & \text { C-reactive protein } \\ \text { PET/CT: } & \begin{array}{l}\text { Positron emission tomography/computed } \\ \text { tomography }\end{array} \\ \text { AJCC: } & \text { American Joint Committee on Cancer } \\ \text { H and E stains: } & \text { Hematoxylin and eosin stain. }\end{array}$

\section{Disclosure}

All authors have nothing to disclose. The abstract of this paper was presented as a poster at the Foundation of the Georgia Academy Family Physicians Annual Research Poster Competition held during the Georgia Academy Family Physicians Annual Meeting and Scientific Assembly, Atlanta, GA, USA in November, 2011.

\section{Acknowledgments}

The authors would like to thank Drs. Amir Hammami and Dylan Marantz for their pathologic services. 


\section{References}

[1] R. Reed, "Acral lentiginous melanoma," in New Concepts in Surgical Pathology of the Skin, W. Hartmann and R. Reed, Eds., pp. 89-90, Wiley, New York, NY, USA, 1976.

[2] D. A. Hudson, J. E. J. Krige, and H. Stubbings, "Plantar melanoma: results of treatment in three population groups," Surgery, vol. 124, no. 5, pp. 877-882, 1998.

[3] Y. J. Chen, C. Y. Wu, J. T. Chen, J. L. Shen, C. C. Chen, and H. C. Wang, "Clinicopathologic analysis of malignant melanoma in Taiwan," Journal of the American Academy of Dermatology, vol. 41, no. 6, pp. 945-949, 1999.

[4] N. M. Luk, L. C. Ho, C. L. Choi, K. H. Wong, K. H. Yu, and W. K. Yeung, "Clinicopathological features and prognostic factors of cutaneous melanoma among Hong Kong Chinese," Clinical and Experimental Dermatology, vol. 29, no. 6, pp. 600-604, 2004.

[5] K. Ishihara, T. Saida, and A. Yamamoto, "Updated statistical data for malignant melanoma in Japan," International Journal of Clinical Oncology, vol. 6, no. 3, pp. 109-116, 2001.

[6] J. A. Al-Maghrabi, A. S. Al-Ghamdi, and H. A. Elhakeem, "Pattern of skin cancer in southwestern Saudi Arabia," Saudi Medical Journal, vol. 25, no. 6, pp. 776-779, 2004.

[7] C. F. Bellows, P. Belafsky, I. S. Fortgang, and D. J. Beech, "Melanoma in African-Americans: trends in biological behavior and clinical characteristics over two decades," Journal of Surgical Oncology, vol. 78, no. 1, pp. 10-16, 2001.

[8] A. Green, M. McCredie, R. MacKie et al., "A case-control study of melanomas of the soles and palms (Australia and Scotland)," Cancer Causes and Control, vol. 10, no. 1, pp. 2125, 1999.

[9] T. S. Wiecker, H. Luther, P. Buettner, J. Bauer, and C. Garbe, "Moderate sun exposure and nevus counts in parents are associated with development of melanocytic nevi in childhood a risk factor study in 1812 kindergarten children," Cancer, vol. 97, no. 3, pp. 628-638, 2003.

[10] P. Kaskel, P. Kind, S. Sander, R. U. Peter, and G. Krähn, "Trauma and melanoma formation: a true association?" British Journal of Dermatology, vol. 143, no. 4, pp. 749-753, 2000.

[11] I. R. Bristow and K. Acland, "Acral lentiginous melanoma of the foot and ankle: a case series and review of the literature," Journal of Foot and Ankle Research, vol. 1, no. 1, 2008.

[12] S. Metzger, U. Ellwanger, W. Stroebel, U. Schiebel, G. Rassner, and G. Fierlbeck, "Extent and consequences of physician delay in the diagnosis of acral melanoma," Melanoma Research, vol. 8, no. 2, pp. 181-186, 1998.

[13] S. L. Soon, A. R. Solomon, D. Papadopoulos, D. R. Murray, B. McAlpine, and C. V. Washington, "Acral lentiginous melanoma mimicking benign disease: the Emory experience," Journal of the American Academy of Dermatology, vol. 48, no. 2, pp. 183-188, 2003.

[14] D. R. Bennett, D. Wasson, J. D. MacArthur, and M. A. McMillen, "The effect of misdiagnosis and delay in diagnosis on clinical outcome in melanomas of the foot," Journal of the American College of Surgeons, vol. 179, no. 3, pp. 279-284, 1994.

[15] E. Tan, S. H. Chua, J. T. E. Lim, and C. L. Goh, "Malignant melanoma seen in a tertiary dermatological centre, Singapore," Annals of the Academy of Medicine Singapore, vol. 30, no. 4, pp. 414-418, 2001. 


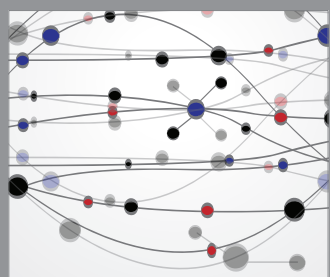

The Scientific World Journal
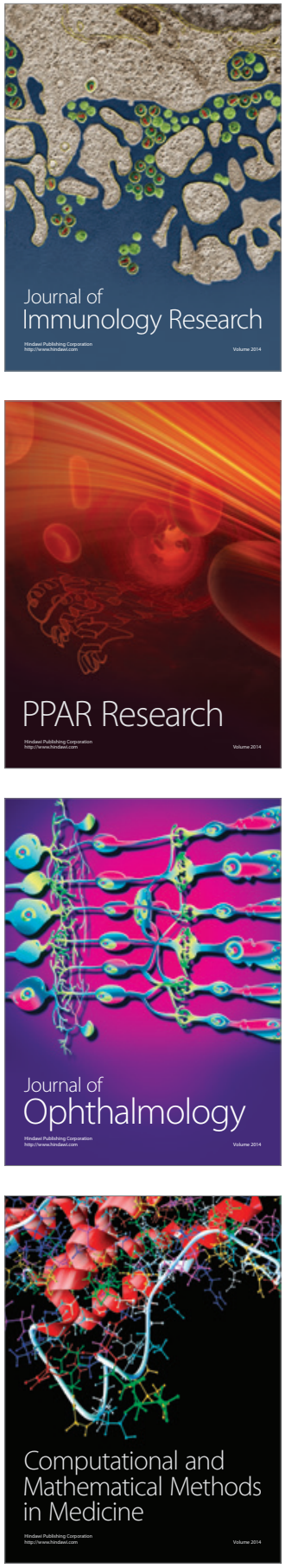

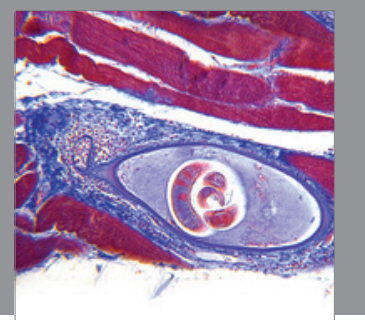

Gastroenterology

Research and Practice
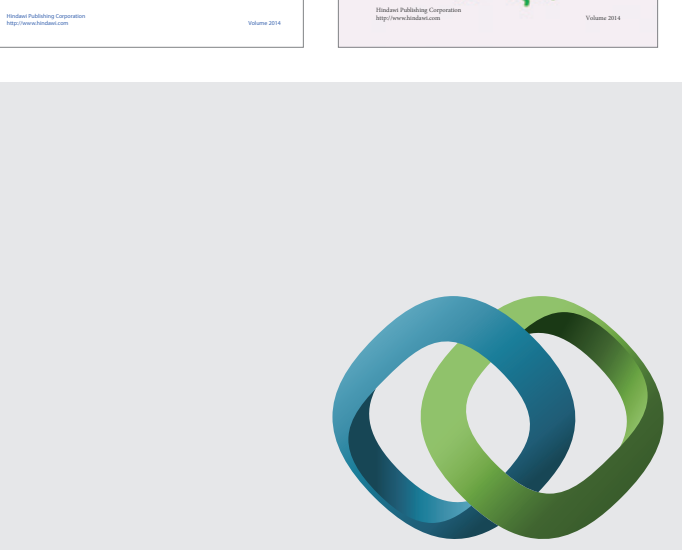

\section{Hindawi}

Submit your manuscripts at

http://www.hindawi.com
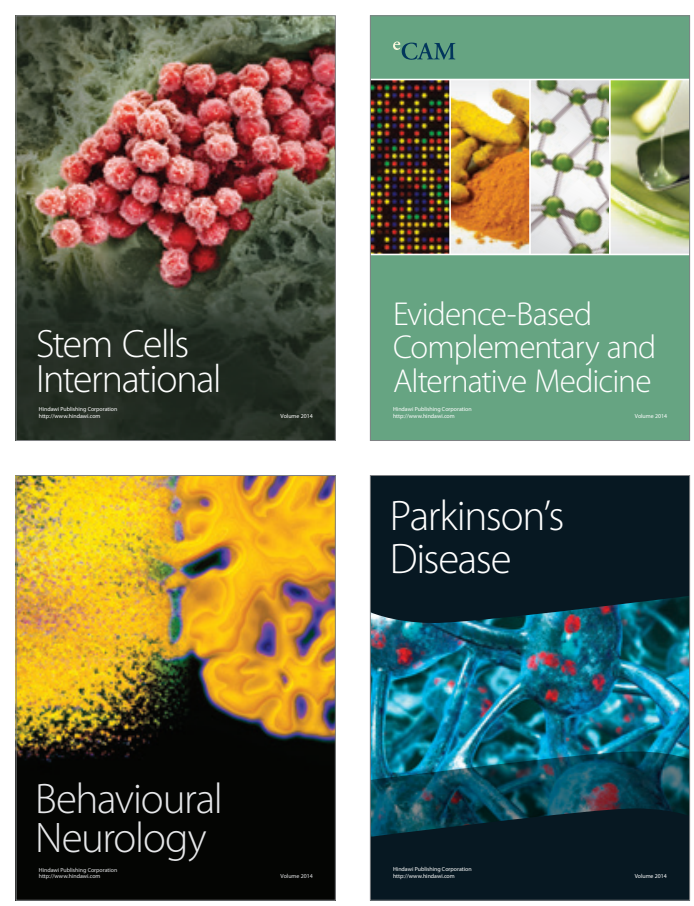

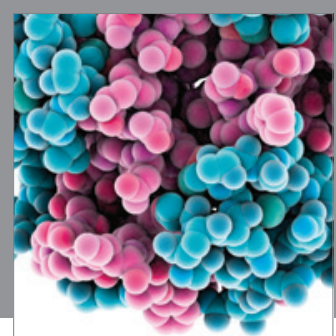

Journal of
Diabetes Research

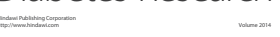

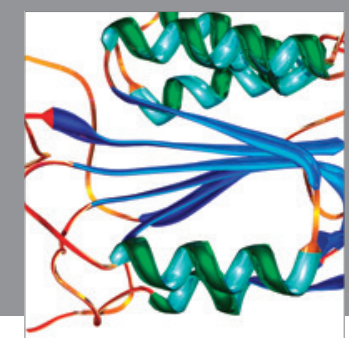

Disease Markers
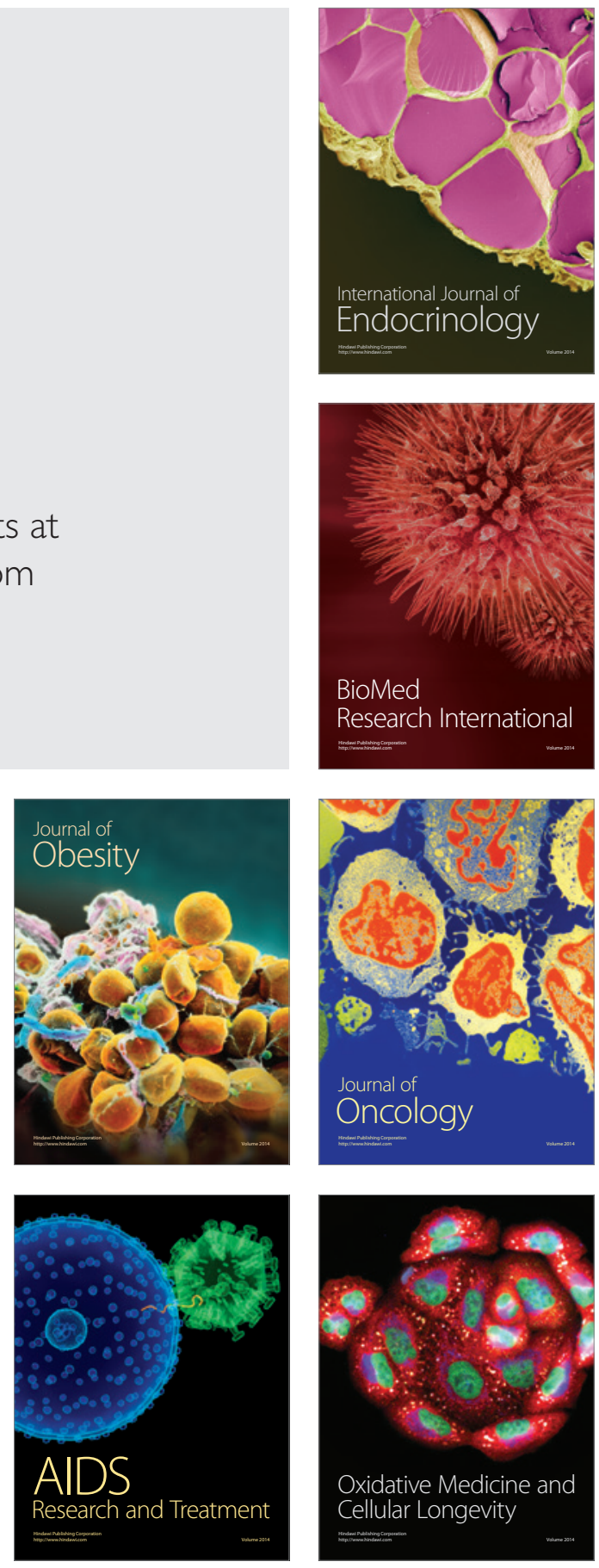